Article

\title{
Carotenoids in Marine Invertebrates Living along the Kuroshio Current Coast
}

Takashi Maoka ${ }^{1}$, Naoshige Akimoto ${ }^{2}$, Miyuki Tsushima ${ }^{3}$, Sadao Komemushi ${ }^{4}$,

Takuma Mezaki ${ }^{5}$, Fumihito Iwase ${ }^{5}$, Yoshimitsu Takahashi ${ }^{6}$, Naomi Sameshima ${ }^{6}$, Miho Mori ${ }^{6}$, and Yoshikazu Sakagami ${ }^{6, *}$

1 Research Institute for Production Development, 15 Shimogamo-morimoto-cho, Sakyo-ku, Kyoto 606-0805, Japan; E-Mail: maoka@mbox.kyoto-inet.or.jp

2 Graduate School of Pharmaceutical Sciences, Kyoto University, Yoshida-shimoadachi-cho, Sakyo-ku, Kyoto 606-8501, Japan; E-Mail: nmakimoto@leto.eonet.ne.jp

3 Kyoto Pharmaceutical University, Misasagi Yamashina-Ku, Kyoto 607-8412, Japan; E-Mail: tsushima@mb.kyoto-phu.ac.jp

4 Osaka City Graduate School of Engineering and Faculty of Engineering, Osaka City University, 3-3-138 Sugimoto, Sumiyoshi-ku, Osaka 558-8585, Japan; E-Mail: volvo.s80.clsssic386@gmail.com

5 Kuroshio Biological Research Foundation, Nishidomari-560, Ootsuki-cho, Kochi 788-0333, Japan; E-Mails: mezaki@kuroshio.or.jp (T.M.); iwase@kuroshio.or.jp (F.I.)

6 Faculty of Agriculture, Kinki University, Nakamachi 3327-204, Nara-shi 631-8505, Nara, Japan; E-Mails: srdkt24134@hera.eonet.ne.jp (Y.T.); ato10min@yahoo.co.jp (N.S.); mori@nara.kindai.ac.jp (M.M.)

* Author to whom correspondence should be addressed; E-Mail: sakagami@nara.kindai.ac.jp; Tel.: +81-742-43-7154; Fax: +81-742-43-1593.

Received: 30 June 2011; in revised form: 31 July 2011 / Accepted: 8 August 2011 / Published: 22 August 2011

Abstract: Carotenoids of the corals Acropora japonica, A. secale, and A. hyacinthus, the tridacnid clam Tridacna squamosa, the crown-of-thorns starfish Acanthaster planci, and the small sea snail Drupella fragum were investigated. The corals and the tridacnid clam are filter feeders and are associated with symbiotic zooxanthellae. Peridinin and pyrrhoxanthin, which originated from symbiotic zooxanthellae, were found to be major carotenoids in corals and the tridacnid clam. The crown-of-thorns starfish and the sea snail D. fragum are carnivorous and mainly feed on corals. Peridinin-3-acyl esters were major carotenoids in the sea snail D. fragum. On the other hand, ketocarotenoids such as 7,8-didehydroastaxanthin and astaxanthin were major carotenoids in the crown-of-thorns 
starfish. Carotenoids found in these marine animals closely reflected not only their metabolism but also their food chains.

Keywords: carotenoid; marine invertebrates; food chain; metabolism

\section{Introduction}

Marine animals, especially marine invertebrates, contain various carotenoids, with structural diversity [1-4]. Interesting structural carotenoids are still being found in marine animals [4]. In general, animals do not synthesize carotenoids de novo, and so those found in animals are either directly accumulated from food or partly modified through metabolic reactions [2]. The major metabolic conversions of carotenoids found in marine animals are oxidation, reduction, transformation of double bonds, oxidative cleavage of double bonds, and cleavage of epoxy bonds [2,3]. Therefore, various structural varieties are found in carotenoids of marine animals [4].

We have studied carotenoids in several marine invertebrates from chemical and comparative biochemical points of view [4]. In the present study, we focused on carotenoids of the corals Acroporajaponica, A. secale, and A. hyacinthus, the tridacnid clam (elongate giant clam) Tridacna squamosa, crown-of-thorns starfish Acanthaster planci, and small sea snail Drupella fragum, inhabiting the Kuroshio current coast. These animals are closely associated within the food chain. Corals and the tridacnid clam are filter feeders and are associated with symbiotic zooxanthellae (dinoflagellate algae). On the other hand, the crown-of-thorns starfish and small sea snail D. fragum are carnivorous and mainly prey upon corals. Therefore, carotenoids that originated from zooxanthellae are passed to starfish and small sea snails through this food chain. In the present paper, we describe the carotenoids of these marine invertebrates.

\section{Results and Discussion}

Structural formulae of carotenoids identified from Acropora corals, the tridacnid clam T. squamosa, starfish $A$. planci, and sea snail D. fragum are shown in Figure 1.

\subsection{Carotenoids of Corals and the Tridacnid Clam}

The carotenoids composition of the corals and the tridacnid clam were similar to each other (Table 1). $\beta, \beta$-Carotene, peridinin (including the $9^{\prime} Z$ isomer), pyrrhoxanthin, diatoxanthin, and diadinoxanthin were found in these animals. These carotenoid patterns resembled those of symbiotic zooxanthellae $[5,6]$. The results indicate that corals and the tridacnid clam directly absorb carotenoids from symbiotic zooxanthellae and accumulate them without metabolic modification. In the eggs of corals, peridinin and pyrroxanthin were present as major carotenoids. It was assumed that peridinin and pyrroxanthin play important roles in reproduction in corals, as with astaxanthin in salmonid fishes [7].

Recently, Daigo et al. studied carotenoids of more than 20 species of coral inhabiting reefs in Okinawa [8]. They reported that carotenoids found in these corals were not only peridinin and 
diadinoxanthin, that originated from symbiotic zooxanthellae, but also zeaxanthin, lutein, and, fucoxanthin, that originated from cyanobacteria, green algae, and diatoms. Cyanobacteria, green algae, and diatoms were epizoic and/or endolithic algae that grew in association with the corals. Corals accumulated carotenoids from these epizoic and/or endolithic algae [8]. However, the present study found that carotenoids in Acropora corals, inhabiting the Kuroshio current coast of Kochi, only consisted of those that originated from zooxanthellae. These differences might reflect the constitution of associating algae with corals.

Peridinin and pyrrhoxanthin were found to be major carotenoids in the tridacnid clam. In general, major carotenoids found in clams are fucoxanthin and its metabolites originating from diatoms [9-11]. On the other hand, neither fucoxanthin nor its metabolites were found in the tridacnid clam. This indicates that the tridacnid clam only ingested carotenoids from dinoflagellate algae. Similar results were reported in carotenoids of the bivalves, Modiolus modiolus and Pecten maximus [12].

Figure 1. Carotenoids identified from Acropora corals, the tridacnid clam T. squamosa, starfish A. planci, and sea snail D. fragum.
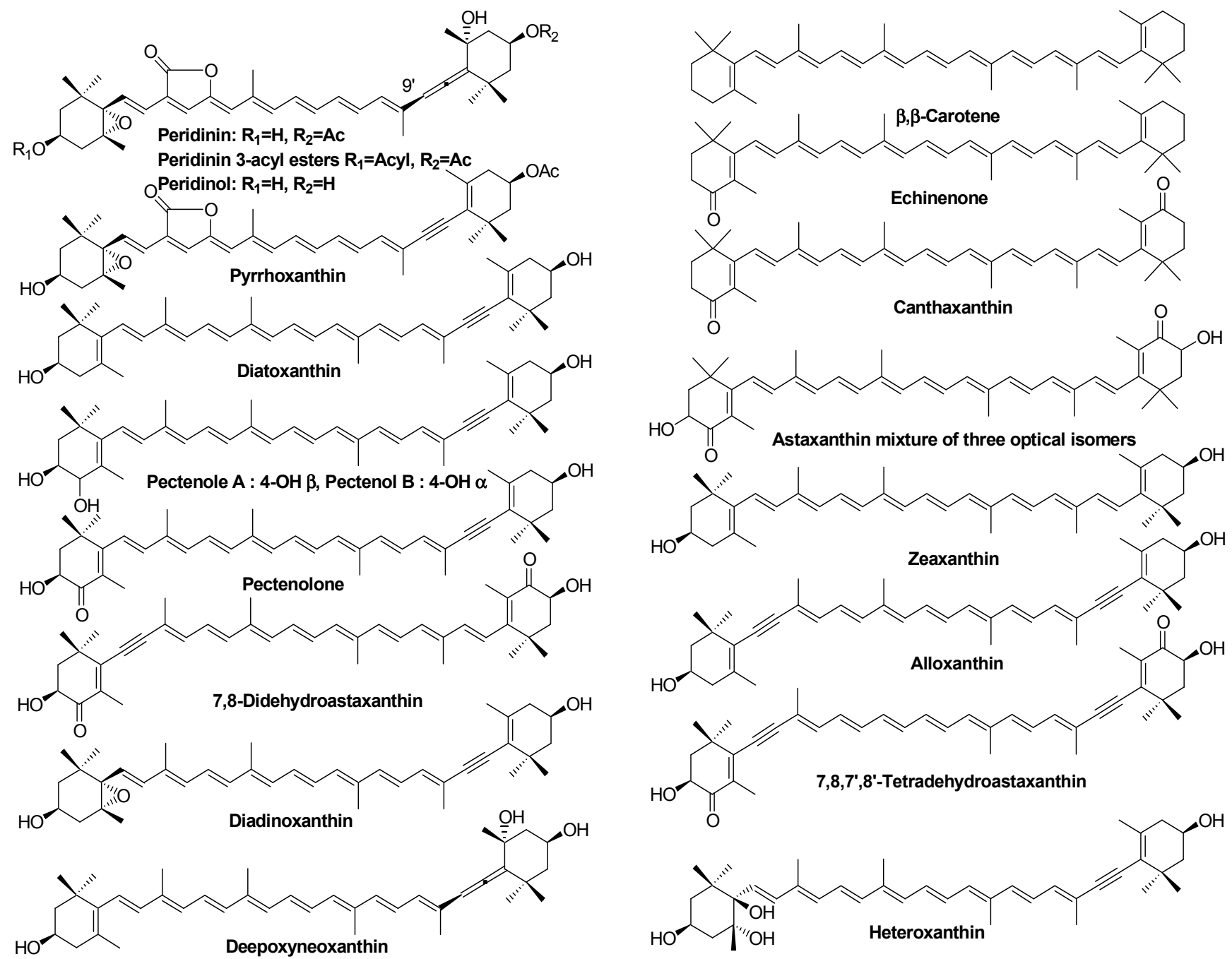
Table 1. Carotenoids of Acropora corals and the tridacnid clam Tridacna squamosa.

\begin{tabular}{lccccc}
\hline & Acropora japonica & & A. secale & A. hyacinthus & Tridacna squamosa \\
\hline & Whole & Egg & Whole & Whole & Mantle and foot \\
\hline Carotenoid content & $3.3(\mathrm{mg} / 100 \mathrm{~g})$ & 0.02 & 2.4 & 2.9 & 10 \\
\hline \multirow{3}{*}{$\beta$-Carotene } & composition $(\%)$ & $\%$ & $\%$ & $\%$ & $\%$ \\
Diatoxanthin & 15.5 & 5.0 & 12.0 & 13.4 & 5.1 \\
Diadinoxanthin & 5.5 & 15.0 & 4.5 & 5.2 & 0.9 \\
Pyrrhoxanthin & 4.5 & 5.0 & 5.0 & 5.5 & 9.2 \\
Peridinin & 45.5 & 20.0 & 50.6 & 40.5 & 10.1 \\
9'Z-Peridinin & 13.0 & 50.0 & 10.0 & 16.0 & 44.1 \\
\hline
\end{tabular}

\subsection{Carotenoids of the Crown-of-Thorns Starfish}

The crown-of-thorns starfish, $A$. planci, is a large, nocturnal sea star that mainly preys upon coral polyps. Like other starfish [13], 7,8-didehydroastaxanthin and astaxanthin were found to be major carotenoids along with pectenolone, 7,8,7',8'-tetradehydroastaxanthin, diatoxanthin, and alloxanthin (Table 2). In general, the starfish can introduce a hydroxy group at C-3 and carbonyl group at C-4 in the $\beta$-end group of carotenoids [6]. So, 7,8-didehydroastaxanthin and astaxanthin were oxidative metabolites of diatoxanthin and $\beta$-carotene, respectively, ingested from dietary corals. Echinenone and canthaxanthin were metabolic intermediates from $\beta, \beta$-carotene to astaxanthin. The acetylenic carotenoids, pectenolone, pectenol A, and pectenol B, were also metabolic intermediates from diatoxanthin to 7,8-didehydroastaxanthin. Peridinol, one of the major carotenoids in the crown-of-thorns starfish, was converted from peridinin, which originated from corals, by hydrolysis. Furthermore, four new carotenoids; 4-ketodeepoxyneoxanthin, 4-keto-4'-hydroxydiatoxanthin, 3'-epigobiusxanthin, and 7,8-dihydrodiadinoxanthin, were isolated [14]. Details of the structural elucidation of those compounds were described previously [14]. In the present paper, the biosynthetic origins of these compounds are discussed (Figure 2). 4-Keto-4'-hydroxydiatoxanthin was one of the metabolic intermediates from diatoxanthin to 7,8-didehydroastaxanthin. 4-Ketodeepoxyneoxanthin might be an oxidative metabolite of deepoxyneoxanthin derived from neoxanthin by deepoxydation. 3'-Epigobiusxanthin might be derived from diadinoxanthin. 7,8-Dihydrodiadinoxanthin, which has a unique single bond in the 7,8-saturated polyene chain, may be a reduction metabolite of diadinoxanthin. Therefore, it was concluded that carotenoids ingested from corals were oxidatively metabolized and accumulated in the crown-of-thorns starfish.

Table 2. Carotenoids of the crown-of-thorns starfish Acanthaster planci.

\begin{tabular}{lcc}
\hline & Whole & Gonad \\
\hline$\beta, \beta$-Carotene & $0.46 \mathrm{mg} / 100 \mathrm{~g}$ & $6.6 \mathrm{mg} / 100 \mathrm{~g}$ \\
Echinenone & 2.1 & 1.4 \\
Canthaxanthin & 1.3 & 1.3 \\
7,8,7',8'-Tetradehydroastaxanthin & 1.6 & 1.6 \\
7,8-Didehydroastaxanthin & 2.0 & 1.6 \\
\hline
\end{tabular}


Table 2. Cont.

\begin{tabular}{lcc}
\hline Astaxanthin & 9.8 & 5.8 \\
Pectenolone & 3.2 & 3.0 \\
Diatoxanthin & 3.2 & 15.8 \\
Alloxanthin & 3.2 & 11.8 \\
Diadinoxanthin & 3.0 & 8.6 \\
7,8-Dihydrodiadinoxanthin & 4.0 & 1.0 \\
3'-Epigobiusxanthin & 2.0 & 1.0 \\
Pectenol A & 2.0 & 1.6 \\
Pectenol B & 4.0 & 3.2 \\
4-Keto-4'-hydroxydiatoxanthin & 5.5 & 1.3 \\
4-Ketodeepoxyneoxanthin & 1.8 & 1.8 \\
Deepoxyneoxanthin & 1.0 & 0.3 \\
Heteroxanthin & 1.2 & 0.6 \\
Peridinol & 13.5 & 3.0 \\
\hline
\end{tabular}

Figure 2. Possible bioformation roots of new carotenoids in crown-of-thorns starfish.
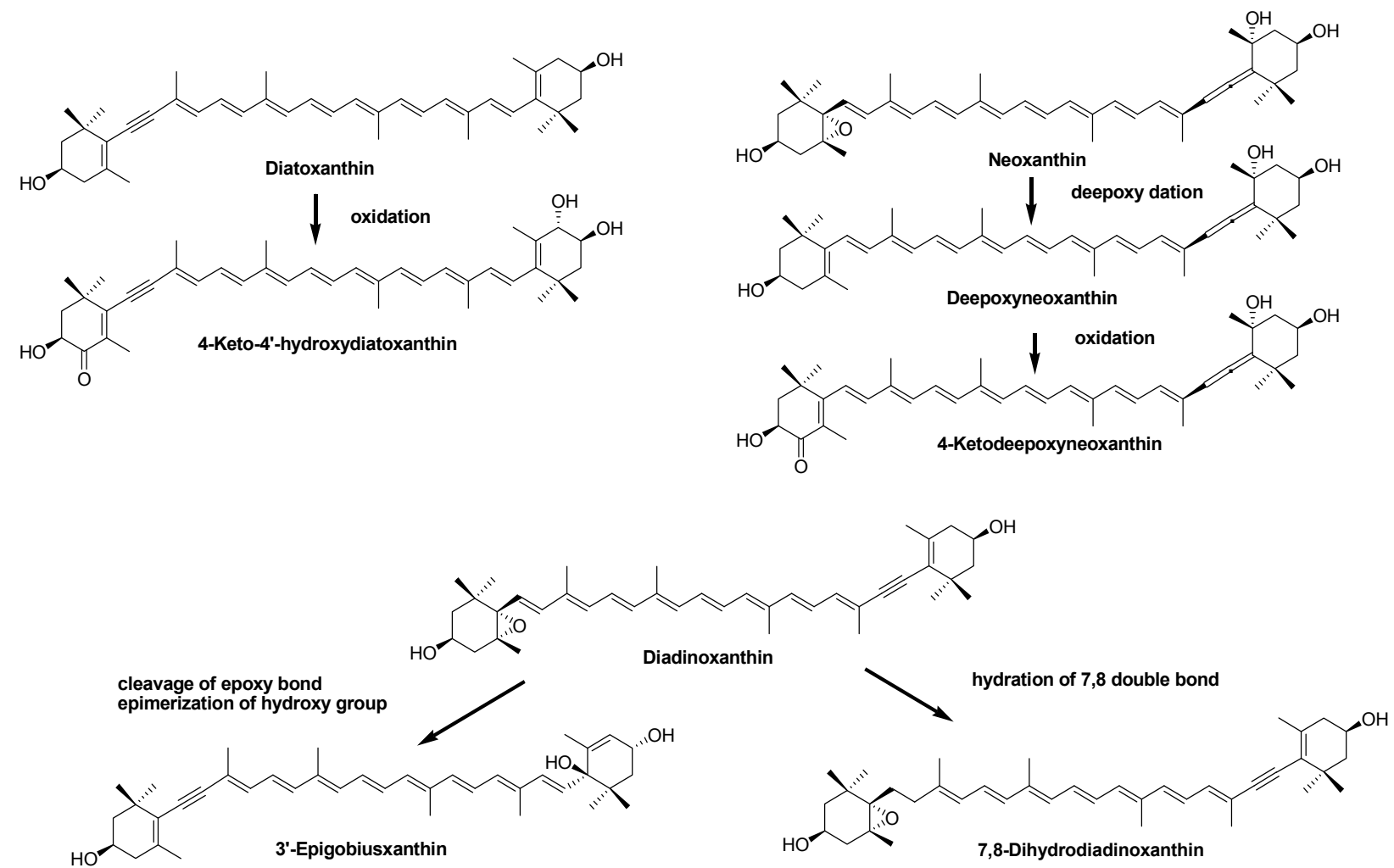

2.3. Carotenoids of the Sea Snail D. fragum

Like the crown-of-thorns starfish, the small sea snail $D$. fragum also feeds on corals. The carotenoid composition of this snail resembled that of the dietary corals (Table 3). This indicated that D. fragum also accumulated carotenoids from dietary corals without metabolic modification, except for the esterification of peridinin. In the present study, peridinin 3-acyl esters were fully characterized based on ${ }^{1} \mathrm{H}-\mathrm{NMR}$ and FAB MS spectral data. The ${ }^{1} \mathrm{H}-\mathrm{NMR}$ signal of H-3 ( $\left.\delta 4.95\right)$, which showed 1.04 ppm 
downfield shift relative to the corresponding signal in peridinin $[15,16]$, indicated that the hydroxy group at C-3 was acylated. Fatty acids esterified with peridinin were assigned as palmitic acid, palmitoleic acid, and myristic acid based on FAB-MS data. Previously, peridinol fatty acid ester was characterized by Moaka et al. [10] and Sugawara et al. [17]. However, peridinin 3-acyl esters have not yet been reported. The origin of zeaxanthin in this snail was unclear. It might have originated from associated algae such as cyanobacteria [8].

Table 3. Carotenoids of the sea snail Drupella fragum.

\begin{tabular}{lc}
\hline Carotenoid content & $\mathbf{4 . 0 3} \mathbf{~ m g} / \mathbf{1 0 0} \mathbf{g}$ \\
\hline$\beta, \beta$-Carotene & composition $(\%)$ \\
Peridinin-3-acyl esters & 10.0 \\
Zeaxanthin & 25.0 \\
Diatoxanthin & 15.0 \\
Diadinoxanthin & 18.3 \\
Pyrrhoxanthin & 9.2 \\
Peridinin & 5.8 \\
\hline
\end{tabular}

\section{Experimental Section}

\subsection{General}

The UV-Visible (UV-VIS) spectra were recorded with a Hitachi U-2001 in diethyl ether (Et ${ }_{2} \mathrm{O}$ ). The positive ion FAB-MS spectra were recorded using a JEOL JMS-700 110A mass spectrometer with $m$-nitrobenzyl alcohol as a matrix. The ${ }^{1} \mathrm{H}-\mathrm{NMR}(500 \mathrm{MHz})$ spectra were measured with a Varian UNITY INOVA 500 spectrometer in $\mathrm{CDCl}_{3}$ with TMS as an internal standard. HPLC was performed on a Shimadzu LC-6AD with a Shimadzu SPD-6AV spectrophotometer set at $470 \mathrm{~nm}$. The column used was a $250 \times 10 \mathrm{~mm}$ i.d., $10 \mu \mathrm{m}$ Cosmosil 5C18-II (Nacalai Tesque, Kyoto, Japan) with acetone:hexane $(3: 7, \mathrm{v} / \mathrm{v})$ at a flow rate of $1.0 \mathrm{~mL} / \mathrm{min}$. The optical purity of astaxanthin was analyzed by chiral HPLC using a $300 \times 8 \mathrm{~mm}$ i.d., $5 \mu \mathrm{m}$ Sumichiral OA-2000 (Sumitomo Chemicals, Osaka, Japan) with $n$-hexane/ $\mathrm{CHCl}_{3}$-ethanol $(48: 16: 0.8, \mathrm{v} / \mathrm{v})$ at a flow rate of $1.0 \mathrm{~mL} / \mathrm{min}$ [18].

\subsection{Animal Material}

The corals A. japonica, A. secale, and A. hyacinthus, the tridacnid clam $T$. squamosa, the crown-of-thorns starfish $A$. planc, and the sea snail D. fragum were collected along the Ootsuki coast, Kochi Prefecture, Japan from July to August 2009 and 2010.

\subsection{Analysis of Carotenoids}

The extraction and identification of carotenoids were carried out according to our routine methods [19]. Carotenoids were extracted from living or fresh animal specimens with acetone. The acetone extract was transferred to ether-hexane (1:1) layer after the addition of water. The total carotenoid contents were calculated employing an extinction coefficient of $\mathrm{E}_{\mathrm{cm}}^{1 \%}=2100$ (astaxanthin) [20] 
for the starfish A. planci and $\mathrm{E}_{\mathrm{cm}}^{1 \%}=1350$ (peridinin) [20] for A. japonica, T. squamosa, and D. fragum at $\lambda$ max. The ether-hexane solution was evaporated. The residue was subjected to HPLC on silica gel. Carotenoid compositions were estimated by the peak area of the HPLC on silica gel with acetone-hexane (3:7) monitored at $470 \mathrm{~nm}$.

Individual carotenoids were identified by UV-VIS (ether), FAB MS, and partial ${ }^{1} \mathrm{H}$ NMR (500 $\left.\mathrm{MHz}, \mathrm{CDCl}_{3}\right)$.

\subsection{Identification of Carotenoids}

Identification of individual carotenoids were carried out on UV-VIS and FAB MS spectral data and compared with chromatographic property with authentic samples [19]. Optical isomer of astaxanthin in the crown-of-thorns starfish Acanthaster planci was analyzed by Chiral HPLC [18]. Astaxanthin fraction in Acanthaster planci was consisted of three optical isomers $\left(3 R, 3^{\prime} R\right):\left(3 R, 3^{\prime} S\right):\left(3 S, 3^{\prime} S\right)$ with a ratio of 32:14:54. Furthermore, peridiniol, peridinin and $9^{\prime} Z$-Peridinin were characterized by ${ }^{1} \mathrm{H}$ NMR [15,16]. Structures of 7,8-ihydrodiadinoxanthin, 3 '-epigobiusxanthin, 4-keto-4'-hydroxydiatoxanthin, 4-ketodeepoxyneoxanthin, and deepoxyneoxanthin were fully characterized by NMR [14].

\subsection{Caracterization of Peridinin-3-acyl Esters}

Peridinin-3-acyl esters. FAB-MS: $m / z 868.5860[\mathrm{M}]^{+}$(calcd. for $\mathrm{C}_{55} \mathrm{H}_{80} \mathrm{O}_{8}, 868.5856$ ) peridinin 3-palmitate, $m / z 866.5698[\mathrm{M}]^{+}$(calcd. for $\mathrm{C}_{55} \mathrm{H}_{79} \mathrm{O}_{8}, 866.5703$ ) peridinin 3-palmitolate, $\mathrm{m} / z$ 840.5550 $[\mathrm{M}]^{+}$(calcd. for $\left.\mathrm{C}_{53} \mathrm{H}_{76} \mathrm{O}_{8}, 840.5547\right)$ peridinin 3-myristate; UV-VIS 455, $475 \mathrm{~nm} ;{ }^{1} \mathrm{H} \mathrm{NMR}\left(\mathrm{CDCl}_{3}\right)$, $\delta 0.88\left(3 \mathrm{H}, \mathrm{t}, J=7.5 \mathrm{~Hz}, \mathrm{CH}_{3}\right.$ in fatty acid moiety), $0.99(3 \mathrm{H}, \mathrm{s}, \mathrm{H}-16), 1.07\left(3 \mathrm{H}, \mathrm{s}, \mathrm{H}-17^{\prime}\right), 1.20(3 \mathrm{H}, \mathrm{s}$ $\mathrm{H}-17), 1.21$ (3H, s H-18), 1.25 (about $24 \mathrm{H}, \mathrm{s},-\mathrm{CH}_{2}$ - in fatty acid moiety), 1.35 (3H, s, H-18'), 1.39 (3H, s, H-16'), $1.41\left(1 \mathrm{H}, \mathrm{dd}, J=13,7 \mathrm{~Hz}, \mathrm{H}-2^{\prime} \beta\right), 1.51\left(1 \mathrm{H}, \mathrm{dd}, J=13,12.5 \mathrm{~Hz}, \mathrm{H}-4^{\prime} \beta\right), 1.64(1 \mathrm{H}$, $\mathrm{dd}, J=12.5,12 \mathrm{~Hz}, \mathrm{H}-2 \alpha \mathrm{eq}), 1.79(1 \mathrm{H}, \mathrm{dd}, J=12,7 \mathrm{~Hz}, \mathrm{H}-4 \beta$ ax $), 1.81$ (3H, s, H-19'), 2.00 (H, ddd, $\left.J=13,4,2 \mathrm{~Hz}, \mathrm{H}-2^{\prime} \alpha\right), 2.04$ (3H, s, $\left.\mathrm{CH}_{3} \mathrm{CO}-\right), 2.23$ (3H, s, H-20), 2.29 (1H, overlapped, $\mathrm{H}-\alpha), 2.28\left(2 \mathrm{H}, \mathrm{t}, J=7.5 \mathrm{~Hz},-\mathrm{CH}_{2}-\mathrm{COOH}\right.$ in fatty acid moiety), $2.41(1 \mathrm{H}$, ddd, $J=14,5,1.5 \mathrm{~Hz}$, H-4a), 4.95 (1H, m, H-3), $5.37\left(1 \mathrm{H}, \mathrm{m}, \mathrm{H}-3^{\prime}\right), 5.74(1 \mathrm{H}, \mathrm{s}, \mathrm{H}-12), 6.06\left(1 \mathrm{H}, \mathrm{s}, \mathrm{H}-8^{\prime}\right), 6.11(1 \mathrm{H}, \mathrm{d}$, $\left.J=11 \mathrm{~Hz}, \mathrm{H}-10^{\prime}\right), 6.38\left(1 \mathrm{H}, \mathrm{dg}, J=14,11 \mathrm{~Hz}, \mathrm{H}-11^{\prime}\right), 6.40(1 \mathrm{H}, \mathrm{d}, J=16 \mathrm{~Hz}, \mathrm{H}-8), 6.46(1 \mathrm{H}, \mathrm{d}$, $\left.J=11 \mathrm{~Hz}, \mathrm{H}-14^{\prime}\right), 6.51\left(1 \mathrm{H}, \mathrm{dd}, J=14,11 \mathrm{~Hz}, \mathrm{H}-15^{\prime}\right), 6.61$ (2H, dd, $\left.J=14,11 \mathrm{~Hz}, \mathrm{H}-11^{\prime}, 15^{\prime}\right)$.

\section{Conclusions}

In conclusion, carotenoids found in the coral A. japonica, clam T. squamosa, starfish A. planci, and sea snail $D$. fragum well reflected not only their metabolism but also the food chain. The accumulation and metabolism of carotenoids that originate from zooxanthellae to the starfish through the food chain are summarized in Figure 3. 
Figure 3. Accumulation and metabolism of carotenoids that originate from zooxanthellae to the starfish and sea snail through the food chain.

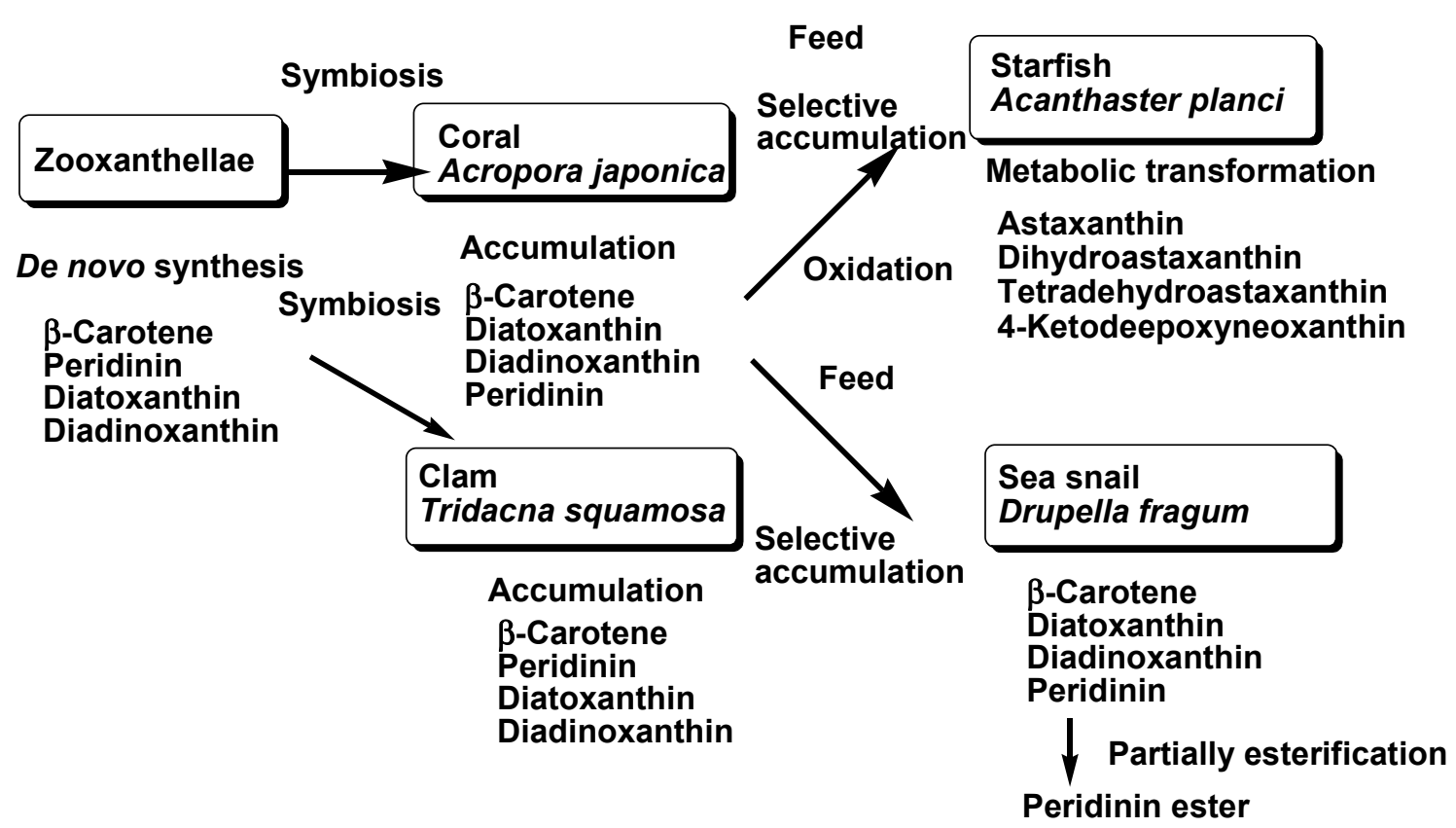

\section{Acknowledgements}

We wish to thank Ryo Harada, a former student of Kinki University (now working in Torii Pharmaceutical Co., Ltd.) for his technical support.

\section{References}

1. Britton, G.; Liaaen-Jensen, S.; Pfander, H. Carotenoids Handbook; Birkhäuser: Basel, Switzerland, 2004.

2. Liaaen-Jensen, S. Biosynthesis and Metabolism. In Carotenoids in Food Chain; Britton, G., Liaaen-Jensen, S., Pfander, H., Eds.; Birkhäuser: Basel, Switzerland, 1998; Volume 3, pp. 359-371.

3. Matsuno, T. Aquatic animal carotenoids. Fish. Sci. 2001, 67, 771-789.

4. Maoka, T. Recent progress in structural studies of carotenoids in animals and plants. Arch. Biochem. Biophys. 2009, 483, 191-195.

5. Skjenstad, T.; Haxo, F.T.; Liaaen-Jensen, S. Carotenoids of clam, coral and nudibranch zooxanthellae in aposymbiotic culture. Biochem. Syst. Ecol. 1984, 12, 149-153.

6. Liaaen-Jensen, S. Biosynthesis and Metabolism. In Carotenoids in Chemosystematics; Britton, G., Liaaen-Jensen, S., Pfander, H., Eds.; Birkhäuser: Basel, Switzerland, 1998; Volume 3, pp. 217-247.

7. Bjerkeng, B. Natural functions. In Carotenoids in Aquaculture: Fish and Crustaceans; Britton, G., Liaaen-Jensen, S., Pfander, H., Eds.; Birkhäuser: Basel, Switzerland, 2008; Volume 4, pp. 237-254. 
8. Daigo, K.; Nakano, Y.; Casareto, B.E.; Suzuki, Y.; Shioi, Y. High-performance liquid chromatographic analysis of photosynthetic pigments in corals: An existence of a variety of epizoic, endozoic and endolithic algae. In Proceedings of the 11th International Coral Reef Symposium, Fort Lauderdale, FL, USA, 7-11 July 2008; pp. 123-127.

9. Maoka, T.; Fujiwara, Y.; Hashimoto, K.; Akimoto, N. Characterizatoin of fucoxanthin and fucoxanthinol esters in the chinese surf clam, Mactra chinensis. J. Agric. Food Chem. 2007, 55, $1563-1567$.

10. Maoka, T.; Akimoto, N.; Yim, M.-J.; Hosokawa, M.; Miyashita, K. A new $\mathrm{C}_{37}$-skeletal carotenoid from the clam, Paphia amabillis. J. Agric. Food Chem. 2008, 56, 12069-12072.

11. Maoka, T.; Akimoto, N.; Murakoshi, M.; Sugiyama, K.; Nishino, H. Carotenoids in clams, Ruditapes philippinarum and Meretrix petechialis. J. Agric. Food Chem. 2010, 58, 5784-5788.

12. Bjerkeng, B.; Hertberg, S.; Liaaen-Jensen, S. Carotenoids in food chain studies-V. Carotenoids of the bivalves Modiolus modiolus and Pecten maximus - structural, metabolic and food chain aspects. Comp. Biochem. Physiol. 1993, 106B, 243-250.

13. Maoka, T.; Tsushima, M.; Matsuno, T. New acetylenic carotenoids from the starfishes Asterina pectinifera and Asterias amurensis. Comp. Biochem. Physiol. 1989, 93B, 829-834.

14. Maoka, T.; Akimoto, N.; Terada, Y.; Komemushi, S.; Harada, R.; Sameshima, N.; Sakagami, Y. Structure of minor carotenoids from crown-of-thorns starfish, Acanthaster planci. J. Nat. Prod. 2010, 73, 675-678.

15. Englert, G. NMR Spectroscopy. In Carotenoids; Britton, G., Liaaen-Jensen, S., Pfander, H., Eds.; Birkhäuser Verlag: Basel, Switzerland, 1995; Volume 1B, pp. 147-260.

16. Haugan, J.A.; Englert, G.; Aakermann, T.; Glinz, E.; Liaaen-Jensen, S. Algal carotenoids 58. Isomerization studies of peridinin. Acta Chem. Scand. 1994, 48, 769-779.

17. Sugawara, T.; Yamashita, K.; Asai, A.; Nagao, A.; Shiraishi, T.; Imai, I.; Hirata, T. Esterification of xanthophylls by human intestinal Caco-2 cells. Arch. Biochem. Biophys. 2009, 483, 205-212.

18. Maoka, T.; Komori, T.; Matsuno, T. Direct resolution of diastereomeric carotenoid-I 3-oxo- $\beta$-end group. J. Chromatogr. A 1985, 318, 122-124.

19. Maoka, T.; Akimoto, N. Natural product chemistry in carotenoid, some experimental techniques for structural elucidation and analysis of natural carotenoids. Carotenoid Sci. 2008, 13, 10-17.

20. Britton, G. UV/Visible Spectroscopy. In Carotenoids; Britton, G., Liaaen-Jensen, S., Pfander, H., Eds.; Birkhäuser Verlag: Basel, Switzerland, 1995; Volume 1B, pp. 13-62.

Samples Availability: Available from the authors.

(C) 2011 by the authors; licensee MDPI, Basel, Switzerland. This article is an open access article distributed under the terms and conditions of the Creative Commons Attribution license (http://creativecommons.org/licenses/by/3.0/). 